Gut, 1978, 19, 1049-1053

\title{
Vasoactive intestinal peptide in man: pharmacokinetics, metabolic and circulatory effects ${ }^{1}$
}

\author{
S. DOMSCHKE, W. DOMSCHKE, S. R. BLOOM ${ }^{2}$, P. MITZNEGG, \\ S. J. MITCHELL, G. LUX, AND U. STRUNZ
}

From the Departments of Medicine and Pharmacology, University of Erlangen-Nürnberg, Erlangen, Germany, and the Department of Medicine, The Royal Postgraduate Medical School, Hammersmith Hospital, London

SUMMARY Graded doses of $0 \cdot 6,1 \cdot 3$, and $3 \cdot 3 \mathrm{pmol} / \mathrm{kg} / \mathrm{min}$ of vasoactive intestinal peptide (VIP) were intravenously infused over 30 minute periods in four healthy volunteers and plasma VIP levels were measured by radioimmunoassay. Even with the smallest dose of VIP, plasma concentrations rose markedly above normal values. Infusion of higher VIP doses resulted in mean plateau levels of circulating VIP which were in the range of VIP values found in the Verner-Morrison syndrome. After cessation of the VIP infusions, plasma VIP levels fell strikingly by first order kinetics with an average disappearance half-time of one minute. The apparent metabolic clearance rate was about $9 \mathrm{ml} / \mathrm{kg} / \mathrm{min}$ and the apparent volume of distribution for VIP was approximately $14 \mathrm{ml} / \mathrm{kg}$. During infusion of the highest VIP dose, previously shown to induce one-fifth maximum pancreatic juice secretion, plasma concentrations of glucose, free fatty acids, and calcium were slightly but significantly raised, the pulse rate and the amplitude of blood pressure were increased, and cutaneous flushing occurred. The spectrum of effects accords well with some abnormalities seen in the Verner-Morrison syndrome. The present data, however, do not support a role for VIP as a circulating hormone, at least under physiological conditions.

Vasoactive intestinal peptide (VIP) was originally isolated from hog small intestine (Said and Mutt, 1970). It has been found in high concentrations not only in the entire gastrointestinal tract (Bloom et al., 1975; Polak et al., 1974) but it has also been shown to be present in central and peripheral neurons (Bryant et al., 1976; Said and Rosenberg, 1976).

It remains a matter of debate whether VIP predominantly acts as a local tissue hormone, plays its major role as a neurotransmitter substance, or acts as a circulating hormone (Bryant et al., 1976). Recently some systemic effects of exogenously administered VIP were evaluated in man (Domschke et al., 1977): VIP acts as a secretin-like partial agonist of human pancreatic exocrine secretion.

To test whether physiologically relevant plasma

\footnotetext{
'This study was supported by a grant (Do 177/4) from the Deutsche Forschungsgemeinschaft, Bonn-Bad Godesberg, W. Germany.

${ }^{2}$ Address for correspondence: Dr S. R. Bloom, Department of Medicine, Hammersmith Hospital, London W12.
}

Received for publication 26 May 1978 levels of VIP had been produced by the originally administered VIP infusions, the same VIP dosage was repeated in additional volunteers and the plasma levels of VIP were measured. On the data obtained a pharmacokinetic analysis was performed. In addition, some routine laboratory parameters were assessed.

\section{Methods}

Four healthy male volunteers (mean age $23 \pm 1$ years, mean body weight $72 \pm 2 \mathrm{~kg}$ ) with no history or physical findings of gastrointestinal or renal diseases were studied. All subjects gave informed written consent. The experimental protocol had been approved by the Local Ethical Committee.

On separate days, in random order, four series of tests were done on each subject. After an overnight fast, the individual study was started. Through an indwelling antecubital catheter, saline solution $(0.15 \mathrm{M} \mathrm{NaCl})$ was infused at $30 \mathrm{ml} / \mathrm{h}$ with a syringe pump (Model 71100, Braun, Melsungen, W. Germany) for a basal period of 30 minutes. Then 
VIP-freshly dissolved in $0.9 \%$ saline-was added to the infusion for 30 minute periods. To check for peptide losses in the infusion apparatus, as VIP is known to adhere strongly to plastic surfaces, the doses administered were verified by determination of immunoreactive VIP in the infusion solution at the outlet of the system, both at the beginning and end of the infusion.

The measured VIP appearing at the peripheral end of the infusion line was less than a third of the calculated concentration. The doses actually given to the subjects were found to be $0.6 \pm 0 \cdot 1,1 \cdot 3 \pm$ $0 \cdot 1$, and $3.3 \pm 0.2 \mathrm{pmol} / \mathrm{kg} / \mathrm{min}$, respectively. A normal saline infusion served as control. Highly purified porcine VIP was a generous gift from Professor V. Mutt, GIH Research Laboratory, Karolinska Institute (Stockholm, Sweden).

Blood samples were taken from a cubital vein catheter at 10,20, and 30 minutes during the basal period; at $0,5,10,15,18,20,22,24,26,28$, and 30 minutes during each VIP infusion; and at $0.5,1,2$, $3,4,5,6,7,8,9,10,12,15,20$, and 30 minutes after the VIP infusion was discontinued. Five millilitre blood samples were collected in chilled tubes containing 1000 kallikrein inactivator units of aprotinin (Trasylol) and $20 \mathrm{U}$ heparin. Samples were immediately centrifuged at $4^{\circ} \mathrm{C}$ and the plasma stored at $-20^{\circ} \mathrm{C}$ until assay.

Estimations of immunoreactive VIP were performed in duplicate and the mean value was used. Results were expressed as mean values \pm SEM. Calculations of pharmacokinetic data were based on the plateau principle described by Goldstein et al. (1974). To determine the disappearance half-time $\left(T_{1 / 2}\right)$ of VIP each subject's basal level was subtracted from all subsequent values. The postinfusion values were normalised by expressing them as a percentage of the previous steady state level. For each subject, these values were converted to their natural logarithms and linear regression anaylsis was performed to yield the slope (elimination constant) $k_{e}$ from which $T_{1 / 2}$ was determined by dividing into 0.693 . The apparent volume of distribution was calculated from the formula: $V=Q /\left(P x k_{e}\right)$, where $\mathrm{V}$ is the volume of distribution in $\mathrm{ml} / \mathrm{kg}$; $\mathrm{Q}$ is the dose of VIP infused in $\mathrm{pmol} / \mathrm{kg} / \mathrm{min}, P$ is the sustained plasma level of VIP above base line in $\mathrm{pmol} / \mathrm{l}$, and $\mathrm{k}_{\mathrm{e}}$ is the elimination constant. The apparent metabolic clearance rate was calculated by dividing the infusion rate in $\mathrm{pmol} / \mathrm{kg} / \mathrm{min}$ by the steady state increment in plasma VIP in pmol/l.

Plasma concentrations of VIP were measured by a radioimmunoassay described in detail elsewhere (Mitchell and Bloom, 1977). Briefly, antisera to pure porcine VIP were raised in rabbits. Radioactive label was prepared by enzymatic iodination, with lactoperoxidase and iodine-125, and was purified by high-resolution ion-exchange chromatography to yield pure monoiodinated VIP (Bloom, 1974). The sensitivity of the assay was such that changes of plasma VIP of $1.5 \mathrm{pmol} / 1$ could be detected with $95 \%$ confidence. There was no cross-reactivity with other gastrointestinal hormones.

In addition to plasma levels of VIP, some routine laboratory and circulatory parameters were measured by conventional methods. Plasma free fatty acids were determined according to Dole and Meinertz (1960). Student's $t$ test for paired values was used in the statistical analysis of these data. Differences were regarded as significant if $P$ was less than 0.05 (Snedecor and Cochran, 1967).

\section{Results}

\section{PHARMACOKINETIC DATA}

Even with the smallest dose of VIP $(0.6 \mathrm{pmol} /$ $\mathrm{kg} / \mathrm{min}$ ), plasma concentrations of VIP (range, 20 to $100 \mathrm{pmol} / \mathrm{l}$ ) rose markedly above basal values $(3 \pm 2 \mathrm{pmol} / \mathrm{l}) .1 \cdot 3$ and $3.3 \mathrm{pmol} / \mathrm{kg} / \mathrm{min}$ of VIP led to extremely high plateau levels of circulating VIP $(154 \pm 22$ and $351 \pm 12 \mathrm{pmol} / \mathrm{l}$; Fig. 1). The steady state increments in plasma VIP achieved during the 30-minute infusions reflect approximately the grading of the infusions (Fig. 1).

As shown in Fig. 1, after cessation of the VIP infusions, plasma concentrations of VIP fell strikingly within seven minutes to about $1 \%$. The course of disappearance was first order with calculated half lives of decay of $0.96 \pm 0 \cdot 10$ and $1 \cdot 15 \pm 0.04$ min, respectively (Fig. 2). Figure 2 shows the normalised data of the postinfusion period plotted semilogarithmically versus time. A good fit on the computer-derived individual linear regression lines was noted with correlation coefficients of not smaller than 0.94 .

The apparent space of distribution, derived from the elimination constants and from the observed increments in plasma VIP during infusion of 3.3 and $1.3 \mathrm{pmol} / \mathrm{kg} / \mathrm{min}$ of VIP was $13 \pm 1$ and $14 \pm 2$ $\mathrm{ml} / \mathrm{kg}$, respectively. The calculated metabolic clearance rate was $9.5 \pm 0.4$ and $8.6 \pm 1.3 \mathrm{ml} / \mathrm{kg} / \mathrm{min}$, respectively.

\section{LABORATORY AND CIRCULATORY \\ PARAMETERS}

During infusion of the highest dose of VIP, plasma concentrations of glucose were significantly raised from a basal level of $5.05 \pm 0.29$ to $5.61 \pm 0.27$ $\mathrm{mmol} / \mathrm{l}$. Plasma levels of free fatty acids were increased from $0.40 \pm 0.06$ to $0.96 \pm 0.09 \mathrm{mmol} / \mathrm{l}$ $(P<0.05)$. The highest VIP dose led to a rise in plasma calcium from $1.84 \pm 0.03$ to $1.93 \pm 0.02$ 
Vasoactive intestinal peptide in man: pharmacokinetics, metabolic and circulatory effects

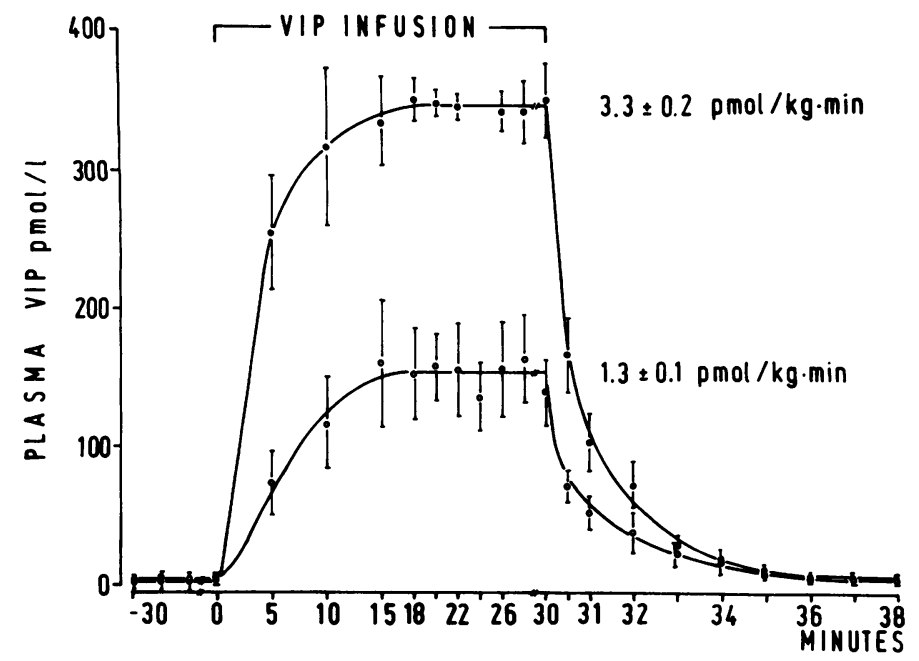

Fig. 1 Plasma immunoreactive VIP in four volunteers during intravenous infusions of $1.3 \mathrm{pmol} V I P / \mathrm{kg} / \mathrm{min}(\bigcirc)$ and $3.3 \mathrm{pmol} V I P / \mathrm{kg} / \mathrm{min}(\Theta) ;$ bar $=S E M$. In a control experiment, normal saline was infused instead of VIP with no change in plasma VIP (not depicted).

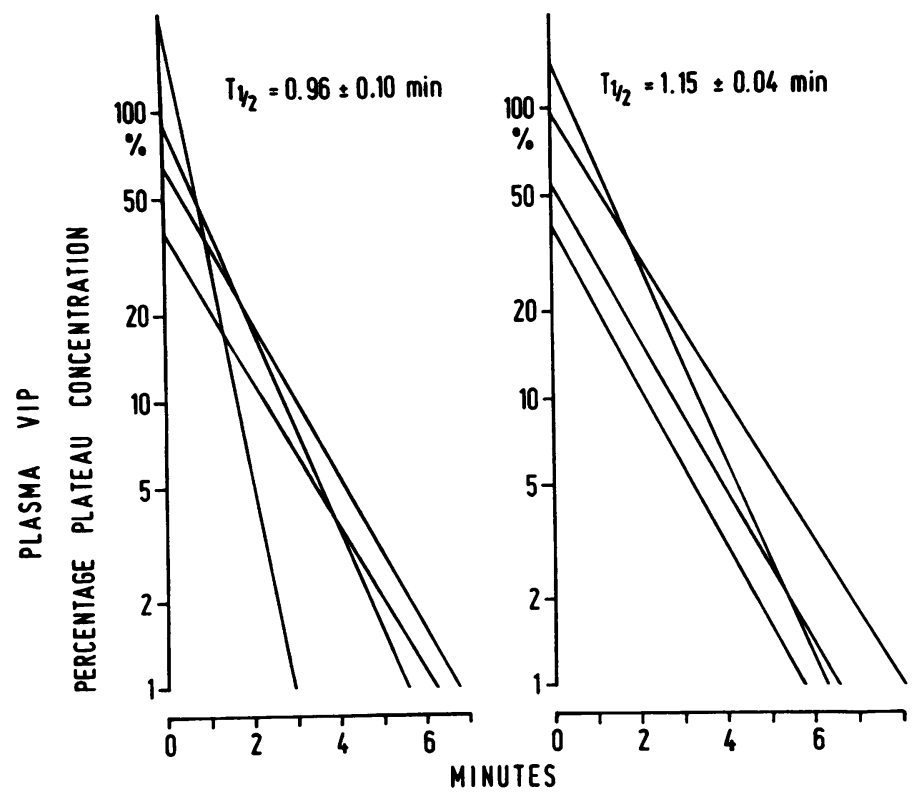

Fig. 2 Individual calculated rates of disappearance from the circulation of immunoreactive VIP in four subjects. Left, after stopping intravenous infusion of $3.3 \mathrm{pmol} / \mathrm{kg} / \mathrm{min}$ of VIP. Right, after infusion of 1.3 $\mathrm{pmol} / \mathrm{kg} / \mathrm{min}$ of VIP.

$\mathrm{mmol} / \mathrm{l}(\mathbf{P}<0.05)$, confirming earlier observations in dogs (Makhlouf et al., 1974). VIP infusion induced a small but significant increase in serum albumin (from $513 \pm 11$ to $554 \pm 8 \mu \mathrm{mol} / \mathrm{l}$ ) which may, in part, have been responsible for the rise in total plasma calcium. Short-term administration of VIP resulted in a modest rise of plasma cholesterol (from $3.5 \pm 0.2$ to $4.0 \pm 0.2 \mathrm{mmol} / \mathrm{l} ; \mathrm{P}<0.05$ ). 
With lower VIP doses, the above-mentioned effects were less pronounced. The blood values of insulin, triglycerides, urea, uric acid, creatinine, SGOT, bilirubin, iron, sodium, potassium, phosphate, and chloride did not change at all during VIP infusion.

At a dosage of $1.3 \mathrm{pmol} / \mathrm{kg} / \mathrm{min}$, VIP infusions invariably led to constant cutaneous flushing, which was most obvious in the head region and which became more intense at a VIP dose of $3.3 \mathrm{pmol} / \mathrm{kg} /$ min. Within five to 10 minutes after the end of VIP administration, flushing disappeared. During VIP infusion, a significant and dose-dependent increase in pulse rate was observed (from $67 \pm 5$ to $102 \pm$ $11 \mathrm{~min}^{-1}$, at $\left.3.3 \mathrm{pmol} \mathrm{VIP} / \mathrm{kg} / \mathrm{min}\right)$. A significant rise in the amplitude of the blood pressure due to VIP was mainly brought about by a lowering of the diastolic BP (from $84 \pm 5$ to $69 \pm 5 \mathrm{mmHg}-$ $P<0.05$-caused by 3.3 pmol $\mathrm{VIP} / \mathrm{kg} / \mathrm{min}$ ). Despite the changes in blood pressure and pulse rate, subjects did not feel uncomfortable during the tests.

\section{Discussion}

The plasma concentrations of VIP measured upon intravenous infusion of VIP in man were in the range of VIP values found in the Verner-Morrison syndrome (between 60-600 pmol/1, Bloom et al., 1973; Bloom and Polak, 1975). The spectrum of effects observed during intravenous infusion of VIP fits well with some abnormalities seen in the Verner-Morrison syndrome-for example, diabetes mellitus, hypercalcaemia, skin flushing. In our experiments, the duration of VIP infusion was probably too short to overcome colonic reabsorption of secretion from the small intestine and to produce watery diarrhoea, the leading feature of the syndrome (Verner and Morrison, 1958). In pigs, the diarrhoeogenic effect of prolonged VIP infusions has been demonstrated only after at least six hours of VIP infusion. Then a copious watery diarrhoea develops (up to $25 \mathrm{ml} / \mathrm{kg}$; Modlin et al., 1977) with a concomitant fall of plasma potassium levels.

The data presented do not support the suggestion that VIP, under physiological conditions, acts as a circulating hormone, as, even with the smallest dose of exogenous VIP, the plasma levels of VIP rose markedly above the normal range of plasma VIP (0.5-21 pmol/1 (Fahrenkrug and Schaffalitzky de Muckadell, 1977; Mitchell and Bloom, 1977). On the other hand, intraduodenal infusion of acid resulted in only a very modest rise (up to $17 \mathrm{pmol} / \mathrm{l}$ ), in normal subjects (Bloom et al., 1978). Moreover, in man, no significant release of endogenous VIP is seen after a meal, which is generally acknowledged as a physiological stimulus (Mitchell and
Bloom, 1977). In dogs, systemic plasma levels of endogenous VIP were reported to be raised by intravenously administered calcium or by infusing 3 or $6 \%$ hypertonic saline or $0.16 \mathrm{~N}$ hydrochloric acid intraduodenally (Ebeid et al., 1977a,b); though these stimuli cannot unequivocally be regarded as physiological.

The low metabolic clearance but rapid removal of VIP from the circulation was unexpected, and resulted in a calculated apparent distribution space which was only a fraction of plasma volume. The most likely explanation for this phenomenon is that, with so rapid a binding and/or destruction rate, presumably involving all tissue beds, the normal distribution space formulae do not properly apply.

The rapid half-life of VIP also militates against a significant role of the peptide as a circulating hormone, in man. Porcine VIP was as rapidly removed from the circulation of man as has been reported for the pig (Bryant et al., 1976). This may provide another piece of indirect evidence that human and porcine VIP molecules may not differ markedly in their amino acid composition. By its short half-life of decay, VIP, which resembles secretin and glucagon in chemical structure and biological activities (Said and Mutt, 1972), is differentiated from the other members of the secretin-family and from other GI peptides except for those like somatostatin (Vale et al., 1976) or enkephalins (Hambrook et al., 1976) which are considered as locally active agents. Since VIP has been shown to occur in high concentrations not only in the bowel but also in other tissues, such as brain and peripheral nervous system (Bryant et al., 1976; Said and Rosenberg, 1976), VIP may, in addition to its possible role as a neurotransmitter, be an important local tissue hormone and thus a member of the paracrine or local hormone system (Pearse, 1976; Pearse et al., 1977).

Finally, our results provide information about some effects of VIP which might emerge if VIP were to be used as a therapeutic agent. According to Said (1975), VIP is promising as a bronchodilator and its peripheral vasodilator action, especially on the coronary circulation, could also prove useful. The circulatory effects of VIP found in man are consistent with its known inotropic and peripheral vasodilatory action in the dog (Said and Mutt, 1970; Said et al., 1972). The observed rise in plasma glucose and free fatty acids can be ascribed to the hepatic glycogenolytic action of VIP(Kerins and Said, 1973) and stimulation of adispose tissue lipolysis (Frandsen and Moody, 1973). It is possible, however, that stimulation of the adrenergic system by the high VIP doses, or enhanced release of glucagon from the pancreas (Kaneto et al., 1977), also contribute to these effects. 
We are grateful for support from the Wellcome Trust.

\section{References}

Bloom, S. R. (1974). Hormones of the gastrointestinal tract. British Medical Bulletin, 30, 62-67.

Bloom, S. R., Bryant, M. G., and Cochrane, J. P. S. (1975). Normal distribution and postprandial release of gut hormones (Abstract). Clinical Science and Molecular Medicine, 49, 3P.

Bloom, S. R., Mitchell, S. J., Greenberg, G. R., Christofides, N., Domschke, W., Domschke, S., Mitznegg, P., and Demling, L. (1978). Release of VIP by duodenal acid in man. Acta Hepatogastroenterology (In Press).

Bloom, S. R., and Polak, J. M. (1975). The role of VIP in pancreatic cholera. In Gastrointestinal Hormones, pp. 635642. Edited by J. C. Thompson. Texas University Press: Austin.

Bloom, S. R., Polak, J. M., and Pearse, A. G. E. (1973). Vasoactive intestinal peptide and watery diarrhoea syndrome. Lancet, 2, 14-16.

Bryant, M. G., Bloom, S. R., Polak, J. M., Albuquerque, R. H., Modlin, I., and Pearse, A. G. E. (1976). Possible dual role for vasoactive intestinal peptide as gastrointestinal hormone and neurotransmitter substance. Lancet, 1, 991-993.

Dole, V. P., and Meinertz, H. (1960). Microdetermination of long-chain fatty acids in plasma and tissue. Journal of Biological Chemistry, 235, 2595-2599.

Domschke, S., Domschke, W., Rösch, W., Konturek, S. J., Sprügel, W., Mitznegg, P., Wünsch, E., and Demling, L. (1977). Vasoactive intestinal peptide: a secretin-like partial agonist for pancreatic secretion in man. Gastroenterology, 73, 478-480.

Ebeid, A. M., Murray, P., and Fisher, J. E. (1977a). Vasoactive intestinal peptide: the fourth physiological gut hormone? (Abstract). Gastroenterology, 72, A-32/1055.

Ebeid, A. M., Murray, P., Soeters, P. B., and Fisher, J. E. (1977b). Release of VIP by calcium stimulation. American Journal of Surgery, 133, 140-144.

Fahrenkrug, J., and Schaffalitzky de Muckadell, O. B. (1977). Radioimmunoassay of vasoactive intestinal polypeptide (VIP) in plasma. Journal of Laboratory and Clinical Medicine, 89, 1379-1388.

Frandsen, E. K, and Moody, A. J. (1973). Lipolytic action of a newly isolated vasoactive intestinal polypeptide. Hormone and Metabolic Research, 5, 196-199.

Goldstein, A., Aronow, L., and Kalman, S. M. (1974). Principles of Drug Action; the Basis of Pharmacology, pp. 311-332. Wiley: New York.

Hambrook, J. M., Morgan, B. A., Rance, M. J., and Smith, C. F. C. (1976). Mode of deactivation of the enkephalins by rat and human plasma and rat brain homogenates. Nature, 262, 782-783.
Kaneto, A., Kaneko, H., Kajinuma, H., and Kosaka, K. (1977). Effect of vasoactive intestinal polypeptide infused intrapancreatically on glucagon and insulin secretion. Metabolism, 26, 781-786.

Kerins, C., and Said, S. I. (1973). Hyperglycemic and glycogenolytic effects of vasoactive intestinal polypeptide. Proceedings of the Society for Experimental Biology and Medicine, 142, 1014-1017.

Makhlouf, G. M., Said, S. I., and Yau, W. M. (1974). Interplay of vasoactive intestinal peptide (VIP) and synthetic VIP fragments with secretin and octapeptide of cholecystokinin (OCTA-CCK) on pancreatic and biliary secretion (Abstract). Gastroenterology, 66, 737.

Mitchell, S. J., and Bloom, S. R. (1977). Measurement of fasting and postprandial VIP in man. Gut, 19, 1043-1048.

Modlin, I. M., Bloom, S. R., and Mitchell, S. J (1977). Role of VIP in diarrhoea (Abstract). Gut, 18, A418-A419.

Pearse, A. G. E. (1976). Peptides in brain and intestine. Nature, 262, 92-94.

Pearse, A. G. E., Polak, J. M., and Bloom, S. R. (1977). The newer gut hormones. Cellular sources, physiology, pathology, and clinical aspects. Gastroenterology, 72, 746761.

Polak, J. M., Pearse, A. G. E., Garaud, J. C., and Bloom, S. R. (1974). Cellular localization of a vasoactive intestinal peptide in the mammalian and avian gastrointestinal tract. Gut, 15, 720-724.

Said, S. I. (1975). Vasoactive intestinal polypeptide (VIP): current status. In Gastrointestinal Hormones, pp. 591-597. Edited by J. C. Thompson. Texas University Press: Austin.

Said, S. I., and Mutt, V. (1970). Polypeptide with broad biological activity: isolation from small intestine. Science, 169, 1217-1218.

Said, S. I., and Mutt, V. (1972). Isolation from porcineintestinal wall of a vasoactive octacosapeptide related to secretin and to glucagon. European Journal of Biochemistry, 28, 199-204.

Said, S. I., Bosher, L. P., Spath, J. A., and Kontos, H. A. (1972). Positive inotropic action of newly isolated vasoactive intestinal polypeptide (VIP) (Abstract). Clinical Research, 20, 29.

Said, S. I., and Rosenberg, R. N. (1976). Vasoactive intestinal polypeptide: abundant immunoreactivity in neural cell lines and normal nervous tissue. Science, 192, 907-908.

Snedecor, G. W., and Cochran, W. G., (1967). Statistical Methods. 6th edn. Iowa University Press: Ames.

Vale, W., Rivier, C., Brown, M., Leppaluoto, J., Ling, N., Monahan, M., and Rivier, J. (1976). Pharmacology of hypothalamic regulatory peptides. Clinical Endocrinology, 5, suppl., 261s-273s.

Verner, J. V., and Morrison, A. B. (1958). Islet cell tumor and a syndrome of refractory watery diarrhea and hypokalemia. American Journal of Medicine, 25, 374-380. 